\title{
Path Analysis of LPO Process Pooling Model under the Perspective of "Internet Plus"
}

\author{
Xian Zhao \\ Oxbridge College \\ Kunming University of Science and Technology \\ Yunnan Ruiyang Law Firm \\ Kunming, China
}

\author{
Wei Chen \\ Yunnan Ruiyang Law Firm \\ Kunming, China
}

\begin{abstract}
With the advancement of China's "the Belt and Road Initiatives", "Going out" Strategies of Chinese enterprises has spawned many multinational enterprises and cross - border projects, and the demand for legal services has also increased rapidly. Whether the Legal counsel, wind control department of enterprises or law firm, if you want to exploit the new markets in this round of "supply side reform" wave, efficiency, cost control and globalization will become the focus. Achieving these goals will require continuous exploration of new legal services, while legal process outsourcing (LPO) will become the most effective means of cross-border legal services. This paper attempts to analyze the cooperation between LPO service providers and Chinese and foreign law firms from the relevant theories of LPO service in order to find out the path of Chinese law firms to participate in LPO outsourcing business.
\end{abstract}

Keywords-legal process outsourcing (LPO); one-stop integrated legal services; legal cost analysis; contract life cycle management

\section{INTRODUCTION}

Knowledge is power, as an important part of knowledge process outsourcing (KPO), legal process outsourcing (LPO) refers to the inclusion of technology in all aspects of legal service products, so that law firms, enterprises and other institutions will be able to outsource the legal service content that can be completed through computer and network technology to LPO service organizations, and achieve delivery directly through the computer, to help law firms, enterprises and other institutions effectively reduce much of simple and repeated work in legal services, and speed up the delivery of legal services. The data analysis and dashboard reports using LPO-related software enable customers (law firms, enterprises or organizations' legal departments, relevant government departments, etc.) to re-examine (identify, select, retain, manage and evaluate) the relation with legal service provider, achieve the optimal allocation of resources, ensure the allocation of different tasks to the legal professionals who meet the requirements according to the type and complexity level of the legal service, supplement with software support, and ultimately maximize cost and efficiency. At present, Legal zoom, a legal service website of the United States, achieves annual income over 100 million dollars by providing legal document creation services; the E-commerce trend of legal advisory services is also happening around us.

\section{THEORIES RELATED TO LEGAL PROCESS OUTSOURCING (LPO)}

\section{A. LPO Business Development Background}

1) Increasingly refined international division of labor: Multinational companies gradually subcontract their non-core business to overseas to achieve maximum profits based on Adam Smith's international division of labor theory. Some middle developed countries and developing countries with rich human resources and cost advantages are making full use of their comparative advantages and are actively involved in this new international division of labor based on the industrial chain.

The initial approach of LPO model is actually outsourcing the legal business to places with low labor costs (such as India, South Africa and the Philippines) to exploit the difference in labor costs, but LPO industry has been formed all over the world in the past few years and grown mature. Today, the greatest feature of LPO is the global operation, which integrates process management and quality control. China has a wealth of legal talent pool, whose knowledge-based labor costs are relatively low and IT industry technology is complete, thus fully owning capacity to contract LPO business.

2) Cost pressures under global economic downturn: Enterprises mainly consider the following two factors: whether they can reduce or completely eliminate some contents of the legal service; how to economically obtain the legal services necessary for them and how to obtain the service more efficiently. In order to effectively reduce the cost of enterprise management, and make the best use of external resources to solve various legal issues, more and more enterprises will adopt the LPO business.

China's economy is also facing the same problem, and the traditional law firms also need to face the enterprises' requirements of high efficiency and legal service cost squeeze, at the same time, traditional legal services also need to accept continuous challenges from information, cloud platform and mobile Internet, as well as the challenges from the next generation of technology in the near future, may be artificial 
intelligence or others ${ }^{1}$. Traditional law firms should take precautions, focus their attention on overseas markets and businesses, and broaden the scope of the legal business with the power of science and technology, so as to cope with the fierce competition in the domestic market.

\section{B. The Main Contents of LPO Business}

The services that can be completed by LPO service providers currently by relying solely on the Internet technology are mainly as follows:

1) Technology assisted review, referred to as TAR for short: US industry commentators generally believe that the review efficiency of manual document is too $10 w^{2}$, and LPO has developed a technology assisted review system for this problem, namely electronic document management, ediscovery and document review functions. The specific contents mainly include legal code, word processing, archiving service, contract management, document compilation, electronic billing, etc. The leading LPO providers are continuing to develop, test and improve the technology assisted review system to provide smarter, less costly legal review process services. At present, the system has been approaching maturity, and the choice of corporate customers is no longer "Should I use LPO service provider", but "Which technology and workflow best suits to my needs?"

2) Contract Lifecycle Management (CLM): For many companies, the traditional contract management model is time-consuming and labor-consuming, and usually does not have a formal workflow, standard template or time guideline. However, the CLM system now utilizes Lean Six Sigma technology to combine the best practices, flexible resources, and optimal technology to redesign the contract review process and facilitate the effective communication and collaboration among the participants of each step from contract creation, review to negotiation. The specific contents include searchable repositories, more and more accurate and complete legal research, consulting, investigation and case analysis functions, communication and accountability management in the workflow process, and some even provide customized indicator board with view and reporting functions.

ROSS is the current variety of legal services in the software leader. It applied the machine learning technology provided by the IBM Watson Artificial Intelligence Supercomputer to the legal field. Its working principle was to search for a large legal and case database and identify possible answers after identifying the questions raised by the natural language. All answers are evaluated and ultimately provide a solution. ROSS has recently been acquired by Dentons, one of the top ten law firms in the world, which has merged with China's Dacheng Law Firm to become the world's largest law firm and the Chinese name of the new law firm follows Dacheng Law Firm.

As early as 2011, a technology company in the United States developed an artificial intelligence software e-discovery to provide legal analysis services to customers, it is extremely efficient, with a few days Time to analyze the 1.5 million files, only charged the customer $\$ 100,000$ cost; and in more than 30 years ago, a few television between the lawsuit, the huge team of lawyers spent several months to analyze the 6 million In this case, the customer spent $\$ 2.2$ million on this.
3) Data extraction: Data extraction technology is to automatically classify files according to some rules (such as filtering the outdated, repetitive, or non-essential content), or consolidate similar files, and even prioritize the presentation of the most important or closest content in searching. The LPO industry is always at the forefront of technological innovation in terms of data extraction and migration of contract or case. The function is often based on the CLM platform application. When companies conduct large acquisitions, large-scale due diligence or cope with audits, they may need to locate, review and extract specific information from thousands of contracts, and this process requires significant time and labor costs. The current technology is mainly to search and position contracts or cases stored in the hard disk, shared files, the Internet and a variety of software, and can index the documents that meet the requirements once finding them, and use optical character recognition technology (OCR) to help extract the text. Then customers can quickly find the useful information that they want from thousands of documents. At the same time, the automatic extraction and classification technologies of metadata can further improve and accelerate the above process, which also greatly reduce the cost compared to the traditional manual data browsing and seeking.

4) Legal cost (expenditure) analysis: The legal cost analysis means that LPO providers use the data analysis technology and combine with specific visualization technologies to analyze and present the historical and continuous data of electronic bills, to help customers achieve a reduction in the overall cost (expenditure) of the legal department. Although some software companies also provide independent services in the field of cost analysis, the functions of LPO providers are more innovative and professional, for they not only provide relevant data, but also organize and interpret these data, collect, analyze and present (in the form of dashboard reports) valuable (or customerspecified) information and many other key indicators from invoices, accounting books, purchase contracts and other files, and conduct benchmark tests of external consultants and suppliers' performance. Customers can more accurately and timely manage information and create business intelligence reports based on the analysis, and provide legal-related spending details for internal legal and financial teams.

It can be seen from the above functions that text processing, coding, data review, risk management, contract drafting, legal research and other non-core business must be based on strong information processing capabilities and high efficiency. LPO service providers have great advantages in this aspect. In addition, the stability and accuracy of LPO service providers are also higher. The work of such basic information processing is usually done by junior lawyers or lawyer assistants in law firms, and the work effect depends to the specified executor's experience and attitude. The work level varies, so does the work result. Obviously, LPO service providers will be more trusted by customers. 


\section{RESEARCH ON COOPERATION MODEL OF LPO SERVICE PROVIDERS AND LAW FIRMS}

With the globalization brought about by the Internet, many law firms in Europe and America are actively rethinking about the business model of cross-border legal services, including participating in LPO or to reconstructing the traditional law firms' pyramid structure ${ }^{3}$. Although many people think that LPO providers have seized a lot of corporate customers, because the former is not actually involved in the proceedings but usually engaged in basic non-litigation business, it is impossible to replace the law firm. However, there are different voices that LPO providers' current working ability has totally been able to replace the employees at lower level in the law firms' pyramid structure, and the efficiency is very high, with the development of artificial intelligence technology, LPO will no longer stay in the human cost arbitrage sooner or later, and a large number of junior staff will be eliminated, and gradually lawyers at high levels will be replace with the improvement of technology and process. Of course, law firms have recognized this issue, and their attitude to the LPO business turns from the initial refusal to cooperation and winwin situation now.

\section{A. The History of Cooperation Mode}

1) Refusal stage: 2006-2008: The emergence LPO service providers in large number began about in 2006, of course, its earliest supporters were companies' internal legal department, rather than law firms. Many large multinational companies' legal department relied on law firms at first in the face of massive information retrieval and a large number of legal affairs, but after several times of cooperation, the high cost and low efficiency of external lawyers made multinational companies choose to develop their own process management and risk control procedures to reduce the dependence on external lawyers, and ultimately derived professional legal service websites such as Legal zoom and LPO providers.

In the early days of the start, LPO providers tried to seek cooperation with large law firms, but the partners and senior lawyers of these firms did not agree that the cooperation between the two would benefit the firms or companies, believing that LPO provider did not enter the substantive litigation field, and their work could not even be described by the term "practice", so they were not substitutes for law firms, for they could not provide strategic, face-to-face, one-on-one legal services. Eventually, LPO provider gave up the initial intention to cooperate. Now the rapid development of LPO business in the world makes the law firms lose a large number of customer sources, and such "zero-sum game" means every penny earned by LPO providers will be the interests lost by law firms. Law firms have lost the opportunity to participate in the initial development of LPO business to participate in its accumulation of original interests and shares.

2) Check-the-Box stage: 2008 - 2011: Companies are sensitive to cost control, and the global recession has become

Traditional law firm often use a pyramid-shaped structure, that is, a very small number of top-level partners, high-level lawyers and general lawyers, a large number of lawyers and assistants. the most efficient catalyst for LPO business expansion. A large number of law firms' clients start to use LPO providers a lot and put pressure on law firms, which is not only reflected by the fact that a large number of companies consult with external lawyers on the necessity for cooperation with LPO providers and specific cooperation programs (RFPs), but also by the increasing number of direct requests for external lawyers to use LPO services. In order to retain the corporate clients, large law firms accepted the advice of corporate legal personnel and quickly changed their attitude, beginning to accept cooperation with LPO providers.

At this time, the cooperation mode between LPO service providers and law firms is passive. There are two main modes: one is that large multinational companies invite law firms to assist LPO providers to design and provide a set of LPO solutions according to company's needs, tightly integrates the program into the overall value proposition of the enterprise, and decompose the legal functions to redesign the workflow, with appropriate cost reductions. Another way is that law firms themselves choose one or more LPO providers to work with themselves for long periods of time (this is the Check-the-Box stage), and when enterprises need to work with LPO service providers, law firms will recommend their own partners. In both ways, the role of law firms in mainly to facilitate the signing of the service agreement between enterprises and LPO providers, assist to complete the contract review and part of the program design work, once the latter two reach an agreement, usually the law firms' work is completed, and they are not actually involved in operation and cooperation.

3) Strategic cooperation: 2011 - 2015: Law firms are increasingly accepting LPO providers' products through extensive cooperation with them ${ }^{4}$, and they also think that this is a way to improve work efficiency and quality, as well as save customers' costs. LPO providers have their own advantages, such as high efficiency, high technology support, high preciseness and convenient legal service delivery capabilities, which can not be matched by law firms. More and more law firms are beginning to agree with LPO business, hoping to increase their own participation, to establish a more in-depth "strategic cooperation" relationship with LPO providers, and even turn this cooperation into their own competitive advantage.

These firms that have accepted the strategic cooperation have be well aware that neither law firms or LPO providers can solely provide a comprehensive, end-to-end, global service to multinational large enterprise customers. Although many law firms may think they have the ability to integrate resources, and even set up overseas branches or lawyer groups, even the world's largest law firm's ability is limited. The most effective legal service delivery model is to build legal communities, in which law firms and LPO providers play key roles in their

$4 \quad$ In May 2011, "American Law Week" published the results of the follow-up study of legal services jointly provided by the law firms and LPO supplier for business, and although a small number of firms seem to worry about LPO's professionalism, the results show that this fear is unfounded. Approximately $75 \%$ of lawyers do not think that they have "reduced the brand image or quality of service" because of cooperation. 
respective areas of expertise. At present, some innovative law firms have begun to openly recognize the cooperation with LPO providers, and announced some of the cooperative products. The two sides have entered the stage of strategic cooperation.

4) Form the community of of interests: 2016 - present: At present, the challenge faced by law firms is how to achieve $24 / 7$ service and global delivery, to enable companies and customers to benefit from better, faster, easier-to-access and low-cost legal services, which ultimately require new service models, greater innovation and remodeling of implementation model of legal services, while globalization and technological progress have always been the advantages of LPO. The problem faced by LPO providers is that they are less professional and have a narrow range of services, while this is just the advantage of law firms. The legal service industry, as a community of interests, needs to find a better way of cooperation, and constantly innovative service products, while law firms and LPO providers complement each other's advantages and disadvantages, to provide comprehensive and complete services for clients in the future.

With the infiltration of capital, we can see that the ownership between law firms and LPO providers becomes increasingly blurred, that is, they have entered the stage of forming the community of interests. LPO providers begin to acquire large law firms, and law firm partners are also looking for external investment business, buying shares of LPO enterprises, and even using their own professional advantage to develop or participate in LPO business.

\section{B. Analysis of the "Internet Technology and Legal Service" Mode in China's Legal Industry}

1) "Internet and legal big data" type: The biggest change that the Internet brings to the legal industry is clearly the big data. In the past, the search of laws and regulations, referee instruments and various legal documents was a very troubled to legal professional. The law was updated faster but the tool books' publishment was more lagging, local regulations could not be found, and the referee documents could not be seen, which not only caused high cost, difficult access and other issues, but also brought the plight of cross-regional practice. With the emergence of "Internet + legal big data", in addition to the emergence of a large number of big data sites, such as China Judgments Online, PKULAW, law-lib, China legal information database, law-star, itslaw, LawXP and Findlaw, which not only made the reach of laws simple and fast, but also made China's judicature increasingly open and transparent.

Among all kinds of information services, big data sites have the widest users, which not only face judges, lawyers, law scholars in universities, law students and other legal community members, but also have more and more common users. The visits to merely China Judgements Online have exceeded 10 billion. Of course, the construction and operation costs of big data sites are the highest. In addition to the government's legal database, the difficulty of privately operated database legal websites is the revenue model. To obtain high hits, the site's browsing must be free, but it is difficult to convert hits into economic benefits; if the browsing is charged, high cost will narrow users, while the site's operating costs are too high, which ultimately leads to the unsustainable situation of low benefits, lacking sustained development of the site.

2) Internet plus marketing" type: The traditional lawyers' case sources have always been dependent on friends, the law firm's reputation and contacts, which often formed the "80/20 law", that is, $80 \%$ of the cases are concentrated on $20 \%$ of the lawyers, and exploiting case became the biggest problem for a lot of young lawyers. As the Internet penetrates all aspects of people's lives, mobile terminal technology becomes more and more convenient and developed, Internet marketing also appears around us with new media, and the legal Internet marketing sites also rise in response to the proper time and conditions. From the PC-end sites at the beginning, such as 66LAW, 148com, etc., developed to mobile phone APP software and push on WeChat Official Accounts, such as YiLv, yunlvshi, etc., these marketing sites recommend lawyers to viewers through interface advertising, push, free online legal advisory services and so on, however, because the lawyers' free consultation is too simple, the web interface design is rough, and there is too much advertising, paid conversion rate is too low. Users of such sites mostly seek legal advice, but visitors mostly think that such sites or APP software is quite mixed, so they do not trust them too much. Senior lawyers do not need such marketing tools, and highquality clients will not find a suitable lawyer in this way.

3) Professional legal service software" type: With the development of mobile terminal technology, many network technology companies or law firms begin to develop professional legal service software, such as qichacha, falvbao, wusongyuedu, qixin, lawspirit, etc., to provide on-line inquiry of laws \& regulations, inquiry of judgment documents, interest calculation, litigation costs calculation, date calculation, corporate credit inquiry, practice tips, and even lawyer vocational training and other services. The users of the software are mainly lawyers, legal personnel and other legal professionals.

Legal professionals participate in the software design, development and post-operation, and even the operator is a professional law firm, with high degree of specialization and practicality, and some have become necessary auxiliary software for lawyers. Their revenue model is mostly the combination of free and paid services, that is, the basic conventional business is free, while high-end business functions are paid services. Taking the current software qichacha as an example, its basic credit report is provided free of charge, such as inquiry of industrial and commercial registration information, business reports, basic litigation involving situation and other functions, but if you want to query more detailed information, such as enterprises' related information, external investment situation, etc. you need to pay to buy professional credit report. Such software generally takes the road of specialization, with good reputation. Not only the 
economic benefits after the development are considerable, but it's also an invisible publicity for the developer. In this aspect, Tiantong Law Firm has already been far ahead, although it has small number of staff, its income is high, and its Internet business model is worth pondering.

4) "Internet Law Firm" model: Traditional law firms are more subject to geographical restrictions, apart from largescale law firms in Beijing and Shanghai, many lawyers' client sources are from their own provinces and cities, despite their high professional level, and it is difficult for them to handle cross-regional cases, not to mention offshore business. However, with the rapid development of Internet technology, Internet law firms begin to appear, such as China's first Internet law firm Duke Lawyers Union. This kind of Internet law firms mostly rely physical firms, which move the business from offline to online and provide cross-regional legal service.

If we say that the Internet only acts as a carrier and tool in the law firms' business in the above situation, then the Ecommerce platform of the legal cloud service that has appeared has completely eliminated the support of physical law firms, which is a functional platform that highly integrates the superior resources of global law services, presents in a variety of forms, and provide standardized legal services, such as Lyun online, ilaw 360 and so on. This kind of website has been close to LPO providers, which can use voice telephone, Internet site, mobile client, mobile WAP, OTT and other information carriers to provide all-weather online and offline legal advice, contract and legal instrument downloading, audit, writing services, litigation business, non-litigation business and other services for global customers and enterprises, and has become well-deserved "Internet law firms". At the same time, the real LPO provider has also existed in China, such as Deanke, Yubo Lawyers Call Center and so on. Although leading suppliers of the global legal support outsourcing services such as CPA Global and Integreon Company have not yet fully stationed in the Chinese market, but it can be expected that this is only a matter of time.

In short, the overall informationization degree in China's legal industry is lower than that of other industries in China or the legal industry in other countries abroad. With the development of "Internet $+"$ and "the Belt and Road Initiatives" abroad, China's legal community should take these two opportunities, expand ideas, actively participate in the competition of global market, improve their own informationization degree and operational ability, and meet the "globalization", "industrialization" and "informationization" era of China's law.

\section{PATH ANALYSIS OF CHINESE LAW FIRMS’ LPO JOINT VENTURE MODEL}

In China, although there have been many types of legal informationization services, Internet technology has been applied to all aspects of the legal industry, but it is not systematic, for enterprises and firms fight separately, and the degree of participation in globalization is low. In the current round of "supply side reform" tide, how to make China's law firms complete the integration of domestic resources and participate in global legal services and LPO business, and let the world see the Chinese lawyers, is now a problem faced by Chinese law firms. From the analysis of the current situation of China's legal service market and the existing Internet service model, Chinese law firms should take use of "the Belt and Road Initiatives" to seize the opportunities of China's LPO business with their own superior resources, adopt a joint venture model, and open up overseas case sources.

\section{A. Offshore Lawyer Team and Platform" Joint Venture Model}

1) Joint venture model: At present, the number of domestic lawyers surges, and the establishment of a large number of individual and small-scale law firms also makes the competition among law firms increasingly intense, coupled with China's economic slowdown, the average litigation and legal service business of domestic law firms are gradually reducing. However, as Chinese enterprises "go out", business such as cross-border mergers and acquisitions, due diligence for investment, contract compliance review, litigation support, risk control and foreign legal research surges, and the above-mentioned foreign-related cases often require foreign lawyers to coordinate and LPO service providers to initially sort out files and extract key information. Therefore, cooperation with LPO service providers is the trend, and there are two modes of the joint venture:

a) Joint venture with Internet technology enterprises: LPO business is an industry combining capital-intensive and knowledge-intensive, to develop a good LPO platform and contract legal outsourcing business, it requires law firms' expertise as well as the participation of Internet information technology companies. China's law firms can introduce Angel investment or high-tech enterprises for financing, cooperate to build LPO integrated platform through the model of joint venture with Internet technology enterprises, and provide clients with document management business integrating technology, information services and legal services. Law firms are responsible for the design of platform functions as well as the completion and supervision of specific outsourcing business, Internet technology companies are responsible for the development of specific platforms, follow-up technical support, the development of new features and information collection. Law firms can not only expand their business, provide LPO outsourcing services, participate in global competition, but they can also reduce the workload of their own cases can through LPO-related software, and even enjoy the additional business brought by LPO services (such as the litigation business of the customer enterprise, paid business of LPO software, etc.).

b) Joint venture with the world's leading LPO service providers: China's law firms also choose the joint venture with one or two overseas leading global LPO service providers to establish a partnership. China's law firms and LPO service providers jointly contract the legal outsourcing business externally, and coordinate based on division of labor internally. LPO service providers provide information 
services, handle the work that can be completed by using Internet technologies, and hand the remaining work over to law firms' offshore lawyer team, which is usually highly specialized and can not rely solely on Internet technology, such as Chinese law research, litigation business and patent services. LPO service providers have the absolute technical advantages and international brand effect, and law firms have professional legal business capacity and brand awareness in the Chinese market, so the two sides can benefit each other and jointly open the market.

\section{2) Platform construction}

a) One-stop integrated legal services: The quality of LPO service depends on its functionality, and focuses on its ability to integrate resources. China's law firms should establish a one-stop legal service platform integrating big data query and statistics, product marketing, professional legal services and offshore lawyer team service in accordance with the needs of the legal industry. This is not just to limit functions to "E-commerce" or "P2P platform" with channel marketing, but also a business platform with more complete function, higher professional level and more extensive range of services. The development of this platform should fully rely on Internet technology, continue to innovate platform software's support and auxiliary functions for all types of litigation and non-litigation business, such as convenient and efficient document management and development, due diligence report, compliance review, law document search services, offshore lawyer team, as well as provision of more detailed and professional research, consulting and litigation services, so that the platform and lawyers build a complete service system.

b) Play the fullest play to platform advantage: The greatest advantage of LPO service is its low cost and high efficiency, so that most companies can afford LPO service providers' fee for long term, while the provision of such whole-process service can also help enterprises avoid legal risks from the source, and achieve maximum service benefits. LPO service providers' comprehensiveness is proportional to service capacity, so compared to China's current computer legal service software whose function is not strong but single, they should be better at using computer technology and software, reducing labor costs, effectively controlling costs, forming platform advantages, and developing to comprehensive and systematic. For the internal of law firms, it can also use the platform's strategic thinking to optimize the management mechanism, to play the greatest effect of management, brand, investment, expertise and other resources nodes in a platform. Law firms can also use the "decentralized" model, to make the internal looser organizational structure with not clear hierarchical structure and more room for development of young lawyers.

Another advantage of platform is the accessibility of communication, the convenience of communication in crossregional service and even in off-shore services as well as the delivery of service outcomes are very important. Legal services rely on communication and the delivery of legal documents. An important evidence determines the final case outcome, LPO platforms not only need to communicate from time to time, but also have to integrate functions such as data processing, file storage and induction, information encryption and real-time communication, which is different from ordinary chatting software, so that communication becomes not only convenient, but also can effectively ensure information security and timely file archiving.

\section{B. Accurate Market Positioning}

1) Ensure expertise: From the strategic perspective, China's law firms should seize China's LPO business before the world's leading suppliers are settled in China develop business extensively. Whether it is LPO business development or LPO product development, compared to a variety of Internet technology companies, law firms have an absolute advantage in expertise. With the improvement of LPO service providers' business level, law firms must maintain the expertise in legal services to control the initiative, and to make LPO service participates in the business between clients and the firms as a third party, let the served enterprises feel a higher level of business ability, rather than let LPO service providers become the dominant side, seize case sources from law firms, and impact lawyer's business with a low price war.

2) Improve service grading and classification: Different customers clearly need different software functions, and there is great difference in the complexity of the service, the associated costs and implementation techniques. The premise of the LPO business is to analyze the customer's needs and help the latter to understand which functions are more appropriate for the target enterprise's situation, budget, demand or more adaptive, entering the grading and classification of clear services, which businesses need to be handled by lawyers and the grade of lawyers, which can be handled with the assistance of computer data.

a) Focus on small and medium enterprises: One of the paradoxes faced by most Chinese law firms is about the SME legal adviser. Small and medium enterprises stand at the bottom of the pyramid in a large number, with non-standard operation, high legal risk, and the need for professional legal services. Law firms love and hate the large number of enterprises. The small and medium-sized customers have the advantage of large number, rich case sources, and the involved parties are easier to communicate with than large enterprises, the follow-up litigation business is also very impressive. But the shortcomings are also very obvious, the involved parties have limited capacity to pay, the work is trivial and the human, time costs are high. In the end, the result of cooperation is that small and medium enterprises think that the lawyer service is not in place, the consultancy costs are too high, while the firms will think that small and medium enterprises pay low but the work is complex, the cost performance is not high, so some firms even give up this part of business.

LPO business can exactly solve the above problem, that is, it provides graded and classified services for different 
customers. The conventional, risk control, due diligence and other business of small and medium-sized enterprises and large enterprises can be handled by the LPO, while the difficult problems or high-end customers and business are handled by the firm lawyers, in this way, it can not only expand business while reducing human resource costs, but can also achieve complement between online and offline services.

b) Positively contract global LPO outsourcing business externally: The misunderstanding of many lawyers is that they think law firms will lose the control power after cooperating with a third-party LPO provider, and become a veto. Such control is more in terms of management rather than ownership, such as Service Level Agreements (SLA) without proper basis or strict metrics. However, if law firms can strictly comply with the SLA agreement and optimize the governance structure, its control of LPO providers can be much higher than that of their own employees. So the law firms should reduce unnecessary worries in this area, and actively explore offshore LPO outsourcing business.

Only large-scale law firms can set up branches widely in the country, and even set up offshore branches. Although some boutique small firms' expertise and business ability are extremely strong, they lose numerous business opportunities due to the size and personnel problems. The LPO business can help these boutique small firms get rid of the dependence on human capital, integrate customers' needs, transfer fixed costs into variable costs, increase productivity utilization through ongoing technology investments and development, and ensure business continuity and global provision of services and delivery capacity, which can create a much greater value than the establishment of several branches. In the stage of strategic collaboration, law firms, by partnering with LPO providers, expand their business scope, provide complete end-to-end service programs, and effectively provide the appropriate legal services for all types of work.

\section{Focus on Brand Promotion and Operation}

1) Separate marketing from business: LPO business highly depends on brand awareness, which is actually the same for law firms. The traditional law firms' marketing model relies mainly on the personal network of lawyers, but the drawbacks of this model are obvious, that young lawyers can not fully obtain case sources or fully developed, and they must spend a lot of their time cultivating customers and maintaining network. Some partners even no longer handle cases in person but put all their energy in soliciting cases, which is not a virtuous way of development for the legal profession. We more recommend marketing separation from business. The marketing department is responsible for marketing, and business personnel can put more energy on product innovation and legal research. In this way, young lawyers can also get sufficient case sources, and develop by relying on the growth of the platform, besides, their dependence on the platform will also be stronger, and the platform can create a brand, achieve mutual benefit, converge new forces and excellent talent, and grow with the team based on the expertise of lawyers.
2) "Internal marketing team and external PR company" mode: As the LPO legal service model is not highly recognized in China, enterprises and law firms are not very familiar with this way, let alone the general public. The top priority for the operation of LPO business, in addition to the high quality of the product, is to allow more enterprises and people to understand this efficient and low-cost legal service model. Law firms are not willing to accept the simple legal document writing business of some common cases due to low fees, but there is a great demand of this part in China. LPO service providers can fully rely on computer technology to generate and provide documents free of charge, so as to gradually open the market. At present, many foreign LPO service providers use the "internal marketing team + external PR company" mode, that is, LPO enterprises set up internal marketing team responsible for the establishment and promotion of products, and the external professional PR company is responsible for brand promotion and customer management. Our LPO companies can also take a similar pattern.

\section{CONCLUSION}

Of course, there are many problems for China to develop LPO business, such as the low penetration rate and awareness, lack of cross-border service personnel, etc., which means that LPO service providers also need to further expand the talent pool and marketing promotion in the future. However, LPO business was still questioned five years ago, but now it is developing fast, so it is believed that the combination of science \& technology and the law will be closer in the future, and the transformation and development of legal affiliated enterprises is the trend.

\section{REFERENCES}

[1] The management and operation of law firms under "Internet + " situation Liu Nanjun, Zhou Xingmin, http: //www.zX-law.cn/area/detail.php/id225.html

[2] Springer International Publishing AG 2017,K. Jacob et al. (eds.), Liquid Legal, Management for Professionals,DOI 10.1007/978-3-319-458687_6

[3] Kurer, P. (2015). Legal and compliance risk. Oxford: Oxford University Press

[4] Talent needs and training model for China to undertake offshore service outsourcing, Meng Hui, Zhang Jinping, "Business economy" [J], 2014 (20) 